\title{
Free Will and Neuroscience: Decision Times and the Point of No Return
}

\author{
Alfred Mele
}

Although I have written many articles and chapters on neuroscientific arguments for the nonexistence of free will, I have not run out of things to say about these arguments. Part of the explanation is that experiments on the topic continue to be conducted and to shed new light on important issues raised by earlier experiments. This is fortunate for me, given that I accepted Bernard Feltz's invitation to write a chapter for this volume.

Experiments performed by neuroscientist Benjamin Libet in the 1980 os pose an alleged challenge to the existence of free will. Some neuroscientists have followed Libet's lead, sometimes using electroencephalography (EEG), as he did, and sometimes using functional magnetic resonance imaging (fMRI), depth electrodes, or subdural grid electrodes. In Effective Intentions (Mele 2009, chs. 3, 4, and 6), I argued that the neuroscientific work discussed there falls well short of justifying the claim that free will is an illusion. My focus was on the data and on whether the data supported certain empirical claims that have been combined with theoretical claims about free will to yield the conclusion that free will does not exist. There are some interesting new data now. In this chapter, I explore the bearing of some studies published after 2009 on the question whether we have convincing neuroscientific evidence for the nonexistence of free will. Section 1 provides some scientific and terminological background. Section 2 tackles a question about the time at which decisions are made in Libet-style experiments in connection with an examination of a familiar neuroscientific argument for the nonexistence of free will. Section 3 addresses a related neuroscientific argument that features a claim about the point of no return for actions studied in experiments of this kind. Section 4 takes up a skeptical argument that might be thought to have a basis in some recent neuroscientific work. Section 5 wraps things up.

Libet makes the following claims: 
The brain "decides" to initiate or, at least, prepare to initiate [certain actions] before there is any reportable subjective awareness that such a decision has taken place.

LIBET 1985, p. 536

If the "act now" process is initiated unconsciously, then conscious free will is not doing it.

LIBET 2001, p. 62

Our overall findings do suggest some fundamental characteristics of the simpler acts that may be applicable to all consciously intended acts and even to responsibility and free will.

LIBET 1985 , p. 563

Associated with these claims is the following skeptical argument about free will. Elsewhere (Mele 2018), I dubbed it the decision-focused skeptical argument, or DSA for short.

1. In Libet-style experiments, all the decisions to act on which data are gathered are made unconsciously.

2. So probably all decisions to act are made unconsciously.

3. A decision is freely made only if it is consciously made.

4. So probably no decisions to act are freely made. ${ }^{1}$

In Mele 2009, I devote a lot of space to showing that premise 1 is not justified by the data and some space to explaining why the generalization in premise 2 is unwarranted. I return to the former matter shortly, after providing some background. An issue with ties to the latter matter is addressed in Section 4.

Decisions to do things, as I conceive of them, are momentary actions of forming an intention to do them. For example, to decide to flex my right wrist now is to perform a (nonovert) action of forming an intention to flex it now (Mele 2003, ch. 9). I believe that Libet understands decisions in the same way. Some of our decisions and intentions are for the nonimmediate future and others are not. I have an intention today to fly to Brussels three days from now, and I have an intention now to click my "save" button now. The former intention is aimed at action three days in the future. The latter intention is about

1 It may be asserted that, strictly speaking, even if no decisions to act are freely made, this does not preclude the existence of free actions. Even if actions that proceed from unfree decisions are not free, what about other actions - actions that do not proceed from decisions (and are not themselves decisions)? I do not pursue this question here. Decisions (or choices) to act are central the philosophical literature on free will, and the discovery that there are no free decisions would be a very serious blow to free will. 
what to do now. I call intentions of these kinds, respectively, distal and proximal intentions (Mele 1992, pp. 143-44, 158, 2009, p. 10), and I make the same distinction in the sphere of decisions to act. Libet studies proximal intentions (or decisions or urges) in particular.

In the studies described in this section, participants are asked to report on when they had certain conscious experiences - variously described as experiences of an urge, intention, or decision to do what they did. After they act, they make their reports. The measure of consciousness in these studies is the participants' reports on this matter. As I put it elsewhere (Mele 2009, p. 22), it is "report-level" consciousness that is at issue.

The expression "W time" or "time W" is sometimes used in the literature on Libet's work as a label for the time at which a participant is first conscious or aware of his proximal intention (or decision or urge) to flex and sometimes for the reported time of first awareness of consciousness of this. The two times may be different, of course; and Libet himself thought that although the average reported time is about 200 milliseconds (henceforth, ms) before muscle motion begins, the actual average time is about $150 \mathrm{~ms}$ before the beginning of muscle motion (1985, pp. 534-35, 2004, p. 128). Here I use "time W" as a label for the actual time of first awareness.

In some of Libet's studies $(1985,2004)$, participants are asked to flex their right wrist whenever they wish. When they are regularly reminded not to plan their wrist flexes and when they do not afterward say that they did some such planning, an average ramping up of EEG activity (starting $55^{\circ} \mathrm{ms}$ before muscle motion begins; $-550 \mathrm{~ms}$, for short) precedes the average reported time of the conscious experience (200 ms before muscle motion begins, $-200 \mathrm{~ms}$ ) by about a third of a second (Libet 1985). Libet claims that decisions about when to flex were made at the earlier of these two times (1985, p. 536).

The initial ramping that I mentioned is the beginning of a readiness potential (RP), which may be understood as "a progressive increase in brain activity prior to intentional actions, normally measured using EEG, and thought to arise from frontal brain areas that prepare actions" (Haggard et al. 2015, p. 325). The significance of RPs is discussed shortly.

Chun Siong Soon and coauthors, commenting on Libet's studies, write: "Because brain activity in the SMA [supplementary motor area] consistently preceded the conscious decision, it has been argued that the brain had already unconsciously made a decision to move even before the subject became aware of it" (2008, p. 543). To gather additional evidence about the proposition at issue, they use fMRI in a study of participants instructed to do the following "when they felt the urge to do so": "decide between one of two buttons, operated by the left and right index fingers, and press it immediately" (p. 543). Soon 
and colleagues find that, using readings from two brain regions (one in the frontopolar cortex and the other in the parietal cortex), they are able to "predict" with about $60 \%$ accuracy (see Soon et al. 2008, supplementary figure 6, Haynes 2011, p. 93) which button participants will press several seconds in advance of the button press (p. 544). ${ }^{2}$

In another study, Soon et al. ask participants to "decide between left and right responses at an externally determined point in time" (2008, p. 544). They are to make a decision about which of two buttons to press when shown a cue and then execute the decision later, when presented with a "respond" cue (see their supplementary material on "Control fMRI experiment"). Soon et al. report that one interpretation of this study's findings is that "frontopolar cortex was the first cortical stage at which the actual decision was made, whereas precuneus was involved in storage of the decision until it reached awareness" (p. 545).

Itzhak Fried, Roy Mukamel, and Gabriel Kreiman record directly from the brain, using depth electrodes (2011). They report that "A population of SMA neurons is sufficient to predict in single trials the impending decision to move with accuracy greater than $80 \%$ already $700 \mathrm{~ms}$ prior to subjects' awareness" (p. 548) of their "urge" (p. 558) to press the key. By "70o ms prior to subjects's awareness," Fried et al. mean 700 ms prior to the awareness time that participants later report: they recognize that the reports might not be accurate (pp. $55^{2-53}, 560$ ). And, unlike Libet, they occasionally seem to treat decisions to press keys as items that are, by definition, conscious (p. 548). Possibly, in their thinking about their findings, they identify the participants' decisions with conscious urges. If that is how they use "decision," their claim here is that on the basis of activity in the SMA they can predict with greater than $80 \%$ accuracy what time a participant will report to be the time at which he was first aware of an urge to press $700 \mathrm{~ms}$ prior to the reported time. But someone who uses the word "decision" differently may describe the same result as a greater than $80 \%$ accuracy rate in detecting decisions $700 \mathrm{~ms}$ before the person becomes aware of a decision he already made. These two different ways of describing the result obviously are very different. The former description does not include an assertion about when the decision was made.

There are grounds for doubt about the accuracy of the reported awareness times in these studies. I have discussed such grounds elsewhere (Mele 2009, ch. 6; see also Maoz et al. 2015, pp. 190-94), and I will not do so again here. Instead I focus on two questions. The first question is this: When are the pertinent decisions made in these studies? The second is a question about the point

2 This is not real-time prediction. 
of no return in action-producing processes. I introduce it in Section 3, in connection with a skeptical argument that is related to DSA.

In Mele 2009, drawing on data of various kinds, I argued that Libet's participants do not make decisions as early as $550 \mathrm{~ms}$ before the beginning of muscle motion $(-550 \mathrm{~ms})$. Drawing on the same data, I also suggested there that early stages of the readiness potential in his main experiment (a type II RP, which begins at $-550 \mathrm{~ms}$ ) may be associated with a variety of things that are not intentions: "urges to (prepare to) flex soon, brain events suitable for being relatively proximal causal contributors to such urges, motor preparation, and motor imagery, including imagery associated with imagining flexing very soon" (p. 56). Call this group of things the early group. As I pointed out, "If RP onset in cases of 'spontaneous' flexing indicates the emergence of a potential cause of a proximal intention to flex, the proximal intention itself may emerge at some point between RP onset and time W, at time W, or after time W: at time $\mathrm{W}$ the agent may be aware only of something - a proximal urge to flex, for example - that has not yet issued in a proximal intention" (p. 57). This point bears on premise 1 of $D S A$, the assertion that in Libet-style experiments, all the decisions to act on which data are gathered are made unconsciously. If proximal decisions to flex - momentary actions of forming proximal intentions to flex are not made before W, Libet's argument for the claim that they are made unconsciously is undercut.

Also relevant in this connection is evidence about how long it takes for a proximal decision or proximal intention to generate relevant muscle motion. Does it take around $550 \mathrm{~ms}$, as Libet's interpretation of his results implies? I discussed this issue in Mele 2009, where I offered a data-based argument for a negative answer (pp. 6o-64). There is additional evidence about this now and about what is represented by readiness potentials.

In Mele 2009, I suggested that some of the participants in Libet's studies may "treat the conscious urge [to flex] as what may be called a decide signal a signal calling for them consciously to decide right then whether to flex right away or to wait a while" (p. 75). Judy Trevena and Jeff Miller later conducted a pair of interesting studies involving a related decide signal. Both studies had an "always-move" and a "sometimes-move" condition (2010, p. 449). In one study, participants in both conditions were presented with either an "L" (indicating a left-handed movement) or an " $\mathrm{R}$ " (indicating a right-handed movement) and responded to tones emitted at random intervals. In the 
sometimes-move condition, participants were given the following instructions: "At the start of each trial you will see an L or an R, indicating the hand to be used on that trial. However, you should only make a key press about half the time. Please try not to decide in advance what you will do, but when you hear the tone either tap the key with the required hand as quickly as possible, or make no movement at all" (p. 449). (The tone may be viewed as a decide signal calling for a proximal decision about whether to tap or not.) In the alwaysmove condition, participants were always to tap the assigned key as quickly as possible after the tone. Trevena and Miller examined EEG activity for the second preceding the tone and found that mean EEG "amplitudes did not differ among conditions" (p. 450). That is, there were no significant differences among pre-tone EEG amplitudes in the following three conditions: alwaysmove; sometimes-move with movement; sometimes-move without movement. They also found that there was no significant lateralized readiness potential (LRP) before the tone (p. 450). Trevena and Miller reasonably regard these findings as evidence that no part of pre-tone EEG represents a decision to move. The mean time "from the onset of the tone to a key press ... was 322 $\mathrm{ms}$ in the always-move condition and $355 \mathrm{~ms}$ in the sometimes-move condition" (p. 450). If and when the tone was among the causes of a proximal intention to press, the mean time from the onset of that intention to a key press was even shorter. And, of course, muscle motion begins before a key press is complete.

In a second study, Trevena and Miller left it up to participants which hand to move when they heard the decide signal. As in the first study, there was an always-move condition and a sometimes-move condition. Trevena and Miller again found that pre-tone EEG "did not discriminate between" trials with movement and trials without movement, "LRP was absent before the tone," and LRP "was significantly positive after the tone for trials in which a movement was made" (p. 453). They conclude, reasonably, that pre-tone EEG "does not necessarily reflect preparation for movement, and that it may instead simply develop as a consequence of some ongoing attention to or involvement with a task requiring occasional spontaneous movements" (p. 454). Regarding muscle activity, measured using electromyography (EMG), the experimenters report that EMG "seemed to start about $150 \mathrm{~ms}$ after the tone" in both "the sometimes-move trials with movements and in the always-move trials" (p. 452). If, in the case of movements, a proximal decision or intention to tap a key followed the tone, then, obviously, the time from the onset of that decision or intention to muscle motion is even shorter. This casts serious doubt on the claim that, on average, proximal decisions or intentions to flex are made or acquired about $55^{\circ} \mathrm{ms}$ prior to muscle motion in Libet's studies. 
As Aaron Schurger, Jacobo Sitt, and Stanislas Dehaene report, "it is widely assumed that the neural decision to move coincides with the onset of the RP" (2012, p. E2909). Like Trevena and Miller and myself, they challenge that assumption. In their view, the brain uses "ongoing spontaneous fluctuations in neural activity" (p. E2904) - neural noise, in short - in solving the problem about when to act in Libet-style studies. A threshold for decision is set, and when such activity crosses it, a decision is made. They contend that most of the $\mathrm{RP}$ - all but the last 150 to $200 \mathrm{~ms}$ or so (p. E2910) - precedes the decision. In addition to providing evidence for this that comes from the work of other scientists, Schurger et al. offer evidence of their own. They use "a leaky stochastic accumulator to model the neural decision" made about when to move in a Libet-style experiment, and they report that their model "accounts for the behavioral and [EEG] data recorded from human subjects performing the task" (p. E2904). The model also makes a prediction that they confirmed: namely, that when participants are interrupted with a command to move now (press a button at once), short response times will be observed primarily in "trials in which the spontaneous fluctuations happened to be already close to the threshold" when the command (a click) was given (p. E2905).

Short response times to the command clicks are defined as the shortest third of responses to the command and are compared to the longest third (p. E2906). It may be suggested that in the case of the short reaction times, participants were coincidentally already about to press the button when they heard the click. To gather evidence about this, the experimenters instructed participants "to say the word 'coincidence' if the click should ever happen just as they were about to move, or were actually performing the movement" (p. E2907). Participants answered affirmatively in only $4 \%$ of the trials, on average; these trials were excluded (p. E2907).

Especially in the case of the study now under discussion, readers unfamiliar with Libet-style experiments may benefit from a short description of my own experience as a participant in such an experiment (see Mele 2009, pp. 34-36). I had just three things to do: watch a Libet clock with a view to keeping track of when I first became aware of something like a proximal urge, decision, or intention to flex; flex whenever I felt like it (many times over the course of the experiment); and report, after each flex, where I believed the hand was on the clock at the moment of first awareness. (I reported this belief by moving a cursor to a point on the clock. The clock was very fast; it made a complete revolution in about 2.5 seconds.) Because I did not experience any proximal urges, decisions, or intentions to flex, I hit on the strategy of saying "now!" silently to myself just before beginning to flex. This is the mental event that I tried to keep track of with the assistance of the clock. I thought of the "now!" 
as shorthand for the imperative "flex now!" - something that may be understood as an expression of a proximal decision to flex.

Why did I say "now!" exactly when I did? On any given trial, I had before me a string of equally good moments for a "now!" - saying, and I arbitrarily picked one of the moments. ${ }^{3}$ But what led me to pick the moment I picked? The answer offered by Schurger et al. is that random noise crossed a decision threshold then. And they locate the time of the crossing very close to the onset of muscle activity - about 100 ms before it (pp. E2909, E2912). They write: "The reason we do not experience the urge to move as having happened earlier than about $200 \mathrm{~ms}$ before movement onset [referring to Libet's partipants' reported W time] is simply because, at that time, the neural decision to move (crossing the decision threshold) has not yet been made" (E2910). If they are right, this is very bad news for Libet. His claim is that, in his experiments, decisions are made well before the average reported W time: $-200 \mathrm{~ms}$. (In a Libet-style experiment conducted by Schurger et al., average reported $\mathrm{W}$ time is $-150 \mathrm{~ms}$ [p. E2905].) As I noted, if relevant proximal decisions are not made before W, Libet's argument for the claim that they are made unconsciously fails.

The explanation Schurger and colleagues offer of their findings features neural noise crossing a threshold for decision. Recall Trevena and Miller's suggestion that pre-tone EEG in their experiment may "simply develop as a consequence of some ongoing attention to or involvement with a task requiring occasional spontaneous movements" (2010, p. 454). If Schurger and coauthors are right, this EEG develops partly as a consequence of neural noise, "ongoing spontaneous fluctuations in neural activity" (p. E2904); involvement with the task recruits neural noise as a kind of tie breaker among equally good options.

Given what I have said so far in this section, how plausible is it that Soon et al. found decisions 7 to 10 seconds in advance of a button press? Partly because the encoding accuracy was only $60 \%$, it is rash to conclude that a decision was actually made at this early time ( 7 to 10 seconds before participants were conscious of a decision). ${ }^{4}$ As I observed elsewhere (Mele 2014, pp. 201-02), it is less rash to infer that brain activity at this time made it more probable that, for example, the agent would select the button on the left than the button on the right. The brain activity may indicate that the participant is, at that point, slightly more inclined to press the former button the next time he or she presses. Rather than already having decided to press a particular button next

3 This is not to say that every moment was equally good. I wanted to avoid lengthening my participation in the experiment unnecessarily.

4 Even if the encoding accuracy were much higher, one might reasonably wonder whether what is being detected are decisions or potential causes of subsequent decisions. 
time, the person may have a slight unconscious bias toward pressing that button.

What about Fried and colleagues? Did they find early decisions? Their findings are compatible with their having detected at $700 \mathrm{~ms}$ before reported $\mathrm{W}$ time an item of one of the kinds mentioned in what I called "the early group": urges to (prepare to) press a key soon, brain events suitable for being relatively proximal causal contributors to such urges, motor preparation, and motor imagery. A spontaneous fluctuation in neural activity may be added to the list. If participants made proximal decisions to press a key, the findings are compatible with their having made those decisions as late as the decision time identified by Schurger and coauthors.

\section{3}

\section{When Do Participants Reach the Point of No Return?}

Some readers who are persuaded that, in the studies I have discussed, decisions are not made at $-550 \mathrm{~ms}$ or earlier may believe that, even so, the point of no return for the action-generating processes is hit at one or another of the early times identified above and that this is bad news for free will. This belief suggests another argument for skepticism about free will. I call it $P S A$, where $P$ stands for "point of no return."

1. In Libet-style experiments, the point of no return for processes that issue in overt actions is reached well before the corresponding decisions are made (anywhere from $55^{\circ} \mathrm{ms}$ to several seconds before muscle motion).

2. So this is probably true of all decisions to act.

3. If the point of no return for an action-generating process is reached well before the corresponding decision is made, then the decision is not freely made.

4. So probably no decisions to act are freely made.

Someone who endorses premise 3 of this argument may contend that if the point of no return for an action is hit well before the corresponding decision is made, the point of no return for the decision is also hit at this early time and that, in order for a decision to be free, there can be no time prior to the decision's being made at which the point of no return for the making of it has been reached. Not everyone will accept this contention, of course; and not everyone will accept premise $3 .{ }^{5}$ But, for my purposes here, premise 3 does not need to be challenged. My concern is premise 1.

5 Compatibilists about free will maintain that free will is compatible with determinism (see McKenna and Coates 2015 for an instructive review). In a deterministic universe, the point of no return for processes is hit very early! 
In a comment on the possibility of "vetoing" an urge, intention, or decision, Libet makes the following observation: "In the absence of the muscle's electrical signal when being activated, there was no trigger to initiate the computer's recording of any RP that may have preceded the veto" (2004, p. 141). Given this fact about the design of Libet's main experiment, his data do not allow us look for a point of no return. Suppose we wanted to use Libet's data to test the hypothesis that the point of no return for muscle motion is hit somewhere between 550 and $250 \mathrm{~ms}$ before muscle motion starts. What we would like to do is to look at the data to see whether we ever get readings that look like type II RPs during that span of time but are not followed by muscle motion. Libet's experimental design does not allow us to do that. In the main experiment, we get readings only when there is muscle motion.

In Mele 2009, I reported that if I had a neuroscience lab, I would conduct a stop-signal experiment of a certain kind to get evidence about the point of no return in Libet-style scenarios (pp. 75-76). Such an experiment has since been conducted, and it is much more elegant than the one I sketched back then.

The experiment (Schultze-Kraft et al. 2016) takes place in three stages. In all three stages, there is a floor-mounted button and a circle presented on a computer monitor. After the circle turns green, participants wait for "a short, selfpaced period of about $2 \mathrm{s"}$ (p. 1080). When they are finished waiting, they may press the button whenever they wish. They earn points if they press while the light is still green, and lose points if they press after the light turns red. The red light is a stop signal.

In stage 1 of the experiment, the stop signals are issued at random times, and the participants are informed of this. Movement times are not predicted. EEG data from this stage are used to "train a classifier to predict upcoming movements in the next two stages" (Schultze-Kraft et al. 2016, p. 1080).

Stage 2 differs from stage 1 in that movement predictions are made in real time using a brain-computer interface (BСІ). Participants are not informed of this before the experiment. The aim is to issue stop signals in time to interrupt the participants' movements.

After participants complete stage 2, they are told that the computer had been predicting what they would do and that "they should try and move unpredictably" (Schultze-Kraft et al. 2016, p. 1080). The participants are now ready for stage 3 , which is just like stage 2 except that they now have the information I just mentioned.

For my purposes, the most interesting finding is the following one: "Despite the stereotypical shape of the RP and its early onset at around 1,00o ms before EMG activity, several aspects of our data suggest that subjects were able to cancel an upcoming movement until a point of no return that was reached around 
200 ms before movement onset" (Schultze-Kraft et al. 2016, p. 1083). If this is when the point of no return is reached, premise 1 of $P S A$ is false and the argument crumbles. ${ }^{6}$

\section{$4 \quad$ Another Skeptical Argument}

It may be thought that the basis for another skeptical argument about free will is present in my discussion of some recent scientific work. Return to the idea advocated by Schurger and coauthors that the neural decision to move in Libet-style studies is produced when neural noise crosses a threshold. It may be claimed that, if this is what happens, a conscious process is not involved in the (relatively proximal) production of the decision and the decision is therefore unfree. It may also be claimed that this conclusion can properly be generalized to all decisions to act. The argument at issue may be set out as follows. I call it $N S A$, where $N$ stands for "noise."

1. In Libet-style experiments, none of the decisions to act on which data are gathered issue from (relatively proximal) conscious processes.

2. So probably no decisions to act issue from (relatively proximal) conscious processes.

3. A decision is freely made only if it issues from a (relatively proximal) conscious process.

4. So probably no decisions to act are freely made.

In Libet-style experiments, participants are instructed to be spontaneous that is, not to think about what to do. The instructions, if followed, keep consciousness out of the relatively proximal decision-producing process. (Consciousness may be causally involved earlier in the process: for example, participants' conscious understanding of the instructions has a claim to being causally relevant to their performance, and a participant may consciously construct or assent to a plan for completing the experiment, as I did.) The main role for consciousness in these experiments is linked to reporting: participants need a conscious event to report to the experimenter in the case of each particular action. In my case, as I have mentioned, that event was a conscious, silent speech act.

So one difference between decisions made in Libet-style experiments (when participants are following the instructions) and some other decisions is that some other decisions are preceded by conscious reasoning about what to do.

6 This point of no return should not be confused with a later one for the completion of the movement - that is, pressing the button (see Schultze-Kraft et al. 2016, p. 1083). 
The existence of this difference challenges the inference made in premise 2 of $N S A$. From the assertion that, when participants are instructed not to think about what to do, consciousness plays no relatively proximal role in the production of their decisions it does not follow that, when people consciously reason about what to do, their conscious reasoning plays no relatively proximal role in the production of their decisions. Someone who wants to argue that, even in the latter case, consciousness plays no role of the kind at issue cannot rely solely on what happens in situations in which there is no conscious reasoning about what to do.

Another difference also merits attention. As I observed, during my stint as a participant in a Libet-style study I arbitrarily picked moments to begin flexing. Arbitrary picking is featured in the Libet-style studies I have described. Participants are said to have decided when to flex a wrist, when to press a key, or which of two buttons to press. There was no reason to prefer a particular moment for beginning to flex a wrist or press a key over nearby moments and (in the study by Soon et al.) no reason to prefer one button over the other. In these experiments, participants select from options they are indifferent about. But in many cases of decision making, we are far from indifferent about some of our options, and many instances of deciding are not instances of arbitrary picking. In typical cases, when we make decisions about matters that are very important to us, after carefully gathering evidence and painstakingly assessing the options, our leading options differ from one another in ways that matter to us, and we do not arbitrarily pick.

The primary upshot of the considerations sketched in this section is easy to see. Arbitrary pickings in Libet-style experiments differ in obvious ways from some of the decisions we make - decisions about matters that we are not indifferent about and that we make after careful reasoning about what to do. And the differences are such that we cannot legitimately generalize from the assertion that conscious reasoning plays no relatively proximal role in the production of the former decisions to the conclusion that this is true of all decisions to act. $^{7}$

The primary purpose of this chapter was to bring relatively recent studies to bear on a pair of neuroscientific arguments - DSA and PSA - for the nonexistence of free will. As I have explained, these studies add to the body of evidence

7 See Mele 2009, pp. $85-87$ for a parallel point about premise 2 of $D S A$. 
supporting the conclusion that both arguments fail. I also argued that a third skeptical argument, $N S A$, fails as well. I do not want to leave readers with the impression that, in my opinion, the problems with these three skeptical arguments that I have focused on here are the only problems with them. Elsewhere, I have argued against the second premise - a generalizing premise - of DSA (Mele 2009, pp. 85-87, Mele 2018), and I have raised worries about the reliability of reported W times (Mele 2009, ch.6). ${ }^{8}$

\section{References}

Fried, I., R. Mukamel, and G. Kreiman. (2011). "Internally Generated Preactivation of Single Neurons in Human Medial Frontal Cortex Predicts Volition." Neuron 69: 548-62.

Haggard, P., A. Mele, T. O'Connor, and K. Vohs. (2015). "Free Will Lexicon." In A. Mele, ed. Surrounding Free Will. New York: Oxford University Press, 319-26.

Haynes, J.D. (2011). "Beyond Libet: Long-term Prediction of Free Choices from Neuroimaging Signals." In W. Sinnott-Armstrong and L. Nadel, eds. Conscious Will and Responsibility. Oxford: Oxford University Press, 85-96.

Libet, B. (1985). "Unconscious Cerebral Initiative and the Role of Conscious Will in Voluntary Action." Behavioral and Brain Sciences 8: 529-66.

Libet, B. (2001). "Consciousness, Free Action and the Brain." Journal of Consciousness Studies 8: $59-65$.

Libet, B. (2004). Mind Time. Cambridge, MA: Harvard University Press.

Maoz, U., L. Mudrik, R. Rivlin, I. Ross, A. Mamelak, and G. Yaffe. (2015). “On Reporting the Onset of the Intention to Move." In A. Mele, ed. Surrounding Free Will. New York: Oxford University Press, 184-202.

McKenna, M. and D.J. Coates. (2015). “Compatibilism.” In Stanford Encyclopedia of Philosophy. Retrieved from https://plato.stanford.edu/entries/compatibilism/.

Mele, A. (1992). Springs of Action: Understanding Intentional Behavior. New York: Oxford University Press.

Mele, A. (2003). Motivation and Agency. New York: Oxford University Press.

Mele, A. (2003). Effective Intentions: The Power of Conscius Will. New York: Oxford University Press.

8 I presented a version of this chapter at the Catholic University of Louvain (August, 2017). I am grateful to the audience for feedback. Parts of this chapter derive from Mele 2009 and 2018. This chapter was made possible through the support of a grant from the John Templeton Foundation. The opinions expressed here are my own and do not necessarily reflect the views of the John Templeton Foundation. 
Mele, A. (2014). "Free Will and Substance Dualism: The Real Scientific Threat to Free Will?" In W. Sinnott-Armstrong, ed. Moral Psychology, Volume 4: Free Will and Moral Responsibility. Cambridge, MA: MIT Press, 195-207.

Mele, A. (2018). "Free Will and Consciousness." In D. Jacquette, ed. Bloomsbury Companion to the Philosophy of Consciousness. London: Bloomsbury Publishing, 371-88.

Schultze-Kraft, M., Birman, D., Rusconi, M., Allefeld, C., Görgen, K., Dähne, S., and Haynes, J.D. (2016). “The Point of No Return in Vetoing Self-Initiated Movements." Proceedings of the National Academy of Sciences 113: 1080-85.

Schurger, A., J.D. Sitt, and S. Dehaene. (2012). "An Accumulator Model for Spontaneous Neural Activity Prior to Self-Initiated Movement." Proceedings of the National Academy of Sciences 109.42: E2904-13.

Soon, C.S., M. Brass, H.J. Heinze, and J.D. Haynes. (2008). “Unconscious Determinants of Free Decisions in the Human Brain." Nature Neuroscience 11: 543-45.

Trevena, J. and J. Miller. (2010). "Brain Preparation Before a Voluntary Action: Evidence Against Unconscious Movement Initiation." Consciousness and Cognition 19: $447-56$. 